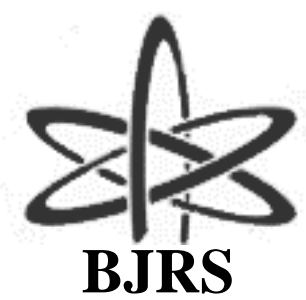

BRAZILIAN JOURNAL

$\mathrm{OF}$

RADIATION SCIENCES

03-1A (2015) 01-10

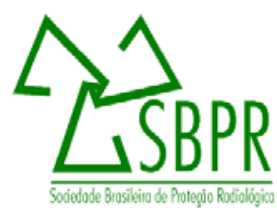

\title{
Web-based system for radiological protection programs: a repository for research, consultation and information
}

\author{
D. S. Levy ${ }^{1,3}$; G. M. A. A. Sordi ${ }^{2,3}$; \\ ${ }^{1} 1$ Instituto de Pesquisas Energéticas e Nucleares - IPEN-CNEN/SP
}

Av. Lineu Prestes 2242 - Cidade Universitária - 05508-000 São Paulo, SP, Brazil

2 Ômiccron Programação Gráfica

Rua Maestro Tom Jobim, 133-12946-638 Atibaia, SP, Brazil

denise@omiccron.com.br

${ }^{3}$ Atomo - Radioproteção e Segurança Nuclear S/C Ltda

Brigadeiro Faria Lima 1572 cj.1513 - 01452-001 São Paulo, SP - Brazil

gmsordi@ipen.br

\begin{abstract}
In order to establish a Radiation Protection Plan or a Radiation Emergency Plan, Brazilian facilities should take into account all procedures based on national and international guidelines and recommendations. This information can be found in several documents published by different organizations over the past decades: the International Commission on Radiological Protection (ICRP), International Atomic Energy Agency (IAEA) and Comissão Nacional de Energia Nuclear (CNEN). Therefore, this project aims the informatization of the radiological protection programs in a single system in order to offer unified programs and inter-related information in Portuguese, providing Brazilian facilities a complete repository for research, consultation and information, combining computer technology and radiological protection in order to enhance the best benefits from information technology. This research work includes programs about: (1) Monitoring of Workplace (Monitoring for External Radiation, Monitoring for Surface Contamination, Monitoring for Air Contamination) and (2) Individual Monitoring (Monitoring of External Exposure and Monitoring of Internal Exposure, Monitoring for Skin and Clothing). WEB platform tools and functionalities were developed according to target public needs, regarding new possibilities of media, mobile access, and information sharing. The servers processing power added to the technology of relational databases allow to integrate information from different sources, enabling complex queries with reduced response time. Moreover, taking into account this is a pioneer project with the prospect of long-term use, the challenge involves the combination of multiple computer technologies that allows a robust, effective and flexible system, which can be easily adapted to future technological innovations.
\end{abstract}


Keywords: Information and Communication Technology; radiological protection programs; ALARA principle; monitoring procedures

\section{INTRODUCTION}

In order to establish a Radiological Protection Plan or a Radiological Emergency Plan, Brazilian facilities should take into account all procedures based on both national and international standards, guidelines and recommendations. This information can be found in several documents published by different organizations over the past decades, namely: the International Commission on Radiological Protection (ICRP), International Atomic Energy Agency (IAEA) and Comissão Nacional de Energia Nuclear (CNEN).

The ICPR provides recommendations and guidance on all aspects to protect the environment and individuals against the harmful effects produced by ionizing radiation. These recommendations are grounded in the reports of the "United Nations Scientific Committee on the Effects of Atomic Radiation” (UNSCEAR) and reports of the "Biological Effects of Ionizing Radiations" (BEIR). The ICRP recommendations are based on their own policy of protection and the organization provides the reasons that led to present their recommendations.

According to the ICRP recommendations and its policy, the IAEA publishes its own recommendations, bringing together the countries affiliated to the UN that use ionizing radiation. Even though the AIEA provides guides to meet all their requirements, the organization does not provide the reasons for these recommendations.

In Brazil, the national government entity is the Comissão Nacional de Energia Nuclear (CNEN), linked to the IAEA and under the Ministry of Science and Technology. This committee has issued a series of standards for radioactive facilities in the country. Even though the Basic Guidelines Protection [01] inform the subject that an adequate and effective Radiation Protection 
Plan should contain, taking into account that plans for similar radioactive installations may have different descriptions, the information is not presented in a logical sequence, nor have detailed and specific comments for programs to the approved.

This project aims the informatization of monitoring policy and techniques programs in a single system in order to offer unified and inter-related information in Portuguese, providing Brazilian facilities a complete repository for research, consultation and information in a quick, integrated and efficient way. In order to meet both national and international recommendations within the scope of this work, there was conducted a comprehensive job of perception about each program contents as well as its real dimension, identifying and detailing the vital parts of programs.

Combining computer technology and radiological protection in order to enhance the best benefits from information technology, this research project aims to provide answers to all reasonable questions applied to different needs, scenarios and situations related to monitoring of workplace and individual monitoring [02 - 03].

\section{METHODOLOGY}

\subsection{Scope and delimitation of the content}

In Brazil facilities involving ionizing radiation are divided into nuclear and radioactive facilities. Nuclear installations cover the entire nuclear fuel cycle, which comprises nuclear materials mining, including power reactors and research, the production of radioisotopes for use in several human activities and also the reprocessing of fuel elements of nuclear reactors. Moreover, the radioactive facilities are those that make use of ionizing radiation in other peaceful applications of nuclear energy like in the industry, medicine, agriculture, environmental protection, among others. This division is due to the fact that the entire nuclear fuel cycle, including reactors, are government monopoly, while all other human activities involving ionizing radiation can be developed and used by the public under government supervision. 
For operational control of exposures to ionizing radiation in any workplace, the ICRP recommends performing an initial radiological evaluation of all aspects of the operation identifying usual and potential predictable exposure in order to make realistic estimates of doses and to determine the radiological protection measures necessary to satisfy the principle of optimization. The organization also recommends establishing a program of operational radiation protection, proportional to the risk, to ensure the effective management of all necessary measures to satisfy the principle of optimization. A monitoring program for the purposes of radiological protection should demonstrate an adequate protection degree and prove that working conditions remain appropriate as time goes by.

Therefore, there were created computerized models that comprise several aspects of the monitoring policy and techniques in a consistent and appropriate manner, in order to interrelate information, currently scattered in various publications and documents. The content includes concepts, definitions and theory about monitoring procedures, such as predominant factors to be considered in monitoring activities, justifications, benefits, optimization and dose limits. Moreover, developed in a modular structure, the system allows to integrate interrelated elements concerning Workplace Monitoring and Individual Monitoring. [04 - 05]

In order to introduce the basic concepts of monitoring, the system presents the criteria used for control of occupational exposures, discussing normal and potential exposures, authority and responsibility, classification of work areas, practical implications and engineering controls, operational procedures, reference levels, types of monitoring and its functions. The system provides detailed information about workplace monitoring and individual monitoring, discussing objectives, routine monitoring and task-related monitoring in each case. Workplace monitoring for air contamination, for example, cover the following topics: more convenient structure, reference level for air contamination, routine monitoring, task-related monitoring and interpretation of results. Also, it was created exclusively for this purpose, an interactive virtual component presenting hypothetical problem-based situations related to incorporation of radioactive materials by workers. Besides workplace monitoring for air contamination, there are 
detailed information about workplace monitoring for external radiation, workplace monitoring for surface contamination, individual monitoring for external exposure, individual monitoring for internal exposure and individual monitoring for skin and clothing contamination.

The content of monitoring programs involves not only the collection and interrelationship of existing information in the publications, but also the possibility of discussions of new approaches from some recommendations, which are not developed, making it difficult to discuss information in a complete and clear way, even from the original publications [06 - 09].

In this sense, one of the subjects to be researched and expanded is about potential exposures. Even though some ICRP publications recommend that the potential exposure should be treated together with normal exposure, in publication 76 [09] The ICRP assumes that in most situations this is not possible, since normal occupational exposure is based on dose limits, while in potential exposure there should be considered the highest doses of the scenario. According to ICRP Publication 76, in its section 62:

"The methods for optimization of radiation protection range from simple common sense to complex quantitative techniques (see Publications 37 and 55; ICRP 1983, 1989). Optimization of protection against potential exposure is still largely unresolved, particularly when probabilities are low and consequences are big (NEA / OECD, 1995). Although the present report conceptually equates risks from normal and potential exposures, simultaneous, formal optimization of protection against both types of exposure would be difficult. However, the use of devices for protection against potential exposures, as outlined here, already includes an element of optimization. Also, the reference risk used in this report corresponds to the risk associated with the highest occupational doses in an optimized operation, rather than to the risk associated with a dose at the occupational dose limit. Still, optimal protection against potential exposures is not necessary achieved at the same level of risk as optimal protection against normal exposures. This is because the costs of reducing risks from normal exposures may be quite different." 
Although this publication recognizes that these two issues should be treated separately, it does not provide specific recommendations. This research work promotes the discussion of this subject, developing the content and introducing potential exposures in more quantitative way than national and international recommendations and providing the notion of different scenarios involving this type of exposure.

\subsection{Web-based system for radiological protection programs}

For the informatization of the monitoring programs, there was developed a platform whose range of features and functionality suits the needs of the corporate public. The system is developed in a modular structure, that allows to integrate interrelated elements on both search and research basis. Moreover, we created updating models where each information is recorded in its most current form in a single record without redundancy, even though it can be found in different subjects or modules. Each module is developed independently and can be inserted, adapted, updated or deleted separately, without prejudice of the other ones. This will allow the program adjusts over time according to the needs identified during the next years.

This project uses the combination of multiple technologies, for both development and infrastructure issues, maximizing the resources available in each technology in order to achieve our goals. Taking into account this is an original project with the prospect of long-term use, it was considered the HTML (XHTML1 STRICT) patterns, according to the W3C (World Wide Web Consortium) recommendations [10]. Considering an infrastructure that supports an average volume of service access, we chose the Linux operating system and MySQL server database [11]. Whether during the implementation phase or hereafter the server has to be rescaled to increased demand, our team can easily migrate the database to a server MSQL Server [12]. This WEB 2.0 concept project makes extensive use of CSS (computer language), allowing it to be easily adapted to new possibilities of media, like mobile access, feeds of content and information sharing. 
There is still a great concern for SEO (computer language) to ensure that the information is wellindexed in the best way possible in the Internet search engines. For the server language development, we chose PHP [13], as it is a widespread technology, well documented with an extensive and active community, and especially for being a dynamic and flexible language, and it is to maintain. Other more modern technologies, up to this date, still have several points of concern regarding the maintenance of source code and flexibility for future development. The technologies mentioned are current pattern programs for this type of development project but shall be constantly revised and may change according to the constant innovations in the information and communication technology that certainly will change in coming years.

\section{FINAL CONSIDERATIONS}

The use of information technology for the radiological protection program for human activities shall help greatly the radioactive facility that requires such use and who needs to implement the program. The main purpose of the use of information technology in the process is to provide the corporate public a complete vehicle that allows detailed research related to monitoring policy and techniques, that allows to size optimization efforts by technology, enabling them to be effective and justified.

The unification of radiological protection monitoring programs implies working on vast and complex content, identifying the most appropriate functional structure in order to develop a project that allows effective access to information and research. The content requires a careful research on content that refers to laws and regulations available in various publications or from different sources (ICPR, IAEA, CNEN). The task of inter-relating all that information is accomplished taking into account established criteria for the development of database relational systems and the features of the information.

The relational database allows the inter-relationship of all relevant co-related information, which are not available in a linear structure or in the same publications. For dimensioning the 
work of informatization and developing the WEB platform according to the needs of the target public, we have conducted an extensive research regarding the possibilities of Information and Communication Technology (TIC) access [14 - 16] throughout the country. The data obtained allowed to mark the effectiveness of this work, such as the proportion of companies using the internet, the proportion of employees who use computers or who have remote access to the system, the proportion of companies with network (LAN, intranet, extranet), activities with the corporate mobile technology, the proportion of employees with internet access at work, average download speed provided by the host service, type of activity performed by the companies using the internet, the proportion of companies with policies access restriction. These data should be periodically reviewed, so that the system will always be in accordance to the public needs. Taking into account this is a pioneer project with the prospect of long-term use, our challenge involves the combination of multiple computer technologies, maximizing the resources available in each one of them, which allows a robust, effective, and flexible system, that can be easily adapted according to future technological innovations. This pioneer project shell help greatly both radioactive facilities and researchers, and it is our target to make it an international reference for Portuguese Spoken countries.

This research work is an initial core that should be extended to other fields of radiological protection, according to the positive Tree, published by IAEA [17] in 1990, which is the more generic and complete tree for an appropriate program of radiation protection. 


\section{REFERENCES}

[1] CNEN - Comissão Nacional de Energia Nuclear. CNEN NN - 3.01, Diretrizes Básicas de Proteção Radiológica, 2005. Brazil.

[2] LEVY, D. S. UNIPRORAD - Unificação dos Programas de Proteção Radiológica Available at: <http://www.uniprorad.com.br> Last accessed: 30 Nov. 2014

[3] LEVY, D.S. Contribution to the informatization of radiation protection programs for nuclear facilities other than nuclear fuel cycle, Master's Thesis, Instituto de Pesquisas Energéticas e Nucleares IPEN/USP, Brazil, 2012

[4] ICRP - International Commission on Radiological Protection. General Principles of Monitoring for Radiation Protection of Workers, publication ICRP 35. Vienna, 1983

[5] ICRP - International Commission on Radiological Protection. General Principles for the Radiation Protection of Workers, publication ICRP 75. Vienna, 1997

[6] ICRP - International Commission on Radiological Protection. Cost-Benefit Analysis in the Optimization of Radiation Protection, publication ICRP 37 Ann. ICRP 10 (2-3). Vienna, 1983

[7] ICRP - International Commission on Radiological Protection. Optimization and Decision-Making in Radiological Protection, Publication ICRP 55. Vienna, 1990

[8] ICRP - International Commission on Radiological Protection. Protection from Potential Exposure - A Conceptual Framework, Publication ICRP 64. Vienna, 1993

[9] ICRP - International Commission on Radiological Protection. Protection from Potential Exposures - Application to Selected Radiation Sources, Publication ICRP 76. Vienna, 1997 
[10] World Wide Web Consortium. Available at: < http://www.w3.org/>.Last accessed: 10 Sept. 2014.

[11] Improving MySQL Query Analyser - Performance Optimization Available at: <http://www.mysql.com/> Last accessed: 10 Sept. 2014.

[12] Sqlserver, Net Solutions. Available at: <http://www.sqlserver.com/> Last accessed: 10 Sept. 2014.

[13] Homepage of Php Available at: <http://www.php.net/> Last accessed: 10 Sept. 2014.

[14] CGI - Comitê Gestor da Internet no Brasil. Pesquisa Sobre o Uso das Tecnologias da Informação e da Comunicação no Brasil 2008, Núcleo de Informação e Coordenação do Ponto BR, São Paulo, 2009

[15] CGI - Comitê Gestor da Internet no Brasil. Pesquisa Sobre o Uso das Tecnologias da Informação e da Comunicação no Brasil 2009, Available at: <http://www.cetic.br/tic/2009/index.htm> Last accessed: 10 Sept. 2014.

[16] CGI - Comitê Gestor da Internet no Brasil. Survey on the use of information and communication technologies in Brazil : ICT Providers 2011, Available at: $<$ http://www.cetic.br/tic/provedores/2010/index.htm> Last accessed: 10 Sept. 2014

[17] IAEA - International Atomic Energy Agency. Recommendation for the Safe Use and Regulation of the Radiation Source in Industry, Medicine and Teaching. IAEA - Safety Series n. 102, Vienna, 1990 